\title{
Proposta metodológica de leitura da paisagem geográfica para o ensino fundamental II
}

\author{
Methodological solution of reading the geographical landscape for the \\ elementary education II
}

\author{
Milaine Aparecida Pichiteli'; Claudivan Sanches Lopes $^{\text {II }}$
}

\begin{abstract}
RESUMO
Neste artigo, apresenta-se parte dos resultados obtidos por meio do desenvolvimento e da implementação de uma proposta metodológica de leitura e análise da paisagem geográfica para o Ensino Fundamental II. Com intenção de permitir ao aluno apropriação/desenvolvimento e uso consciente do conceito científico de paisagem, essa pesquisa orientou-se pela abordagem colaborativa, sendo assim, duas professoras da rede básica de ensino, do Núcleo Regional de Educação de Maringá-PR, foram convidadas a contribuir durante todas as etapas de desenvolvimento da proposta metodológica, como também na implementação e na análise dos resultados. Por meio dessa proposta, deseja-se contribuir no ensino-aprendizagem dos conteúdos geográficos e que, por meio destes, o aluno se torne cada vez mais crítico e engajado na sociedade em que está inserido.
\end{abstract}

Palavras-chave: Paisagem; Ensino de Geografia; Ensino fundamental II

\section{ABSTRACT}

In this paper, presents some of the results obtained through the development and implementation of a methodological solution of reading and analysis of the geographical landscape for the Elementary Education II. With intent to enabling the student for the ownership/development and the conscious use of scientific concept of landscape, this research was based on the collaborative approach, therefore, two elementary teachers of the Regional Education Center of Maringá-PR, were invited to contribute during all stages of development of the methodological proposal, as well as the implementation and analysis of the results. Through this proposal we want to contribute to the teaching-learning of geographic content and that through these, the student becomes increasingly critical and engaged in society which is inserted.

Keywords: Landscape; Geography Teaching; Elementary Education II

\section{INTRODUÇÃO}

O presente artigo expõe parte dos resultados de pesquisa de mestrado desenvolvida junto ao Programa de Pós-Graduação em Geografia da Universidade Estadual de Maringá-PR. Seu objetivo é apresentar uma proposta metodológica de leitura da paisagem geográfica para o ensino fundamental II. Com caráter qualitativo, a investigação se situa no âmbito das pesquisas ativas em educação com abordagem

IDoutoranda do Programa de Pós-Graduação em Geografia Humana - USP. E-mail: milainepichiteli@hotmail.com ORCID: https://orcid.org/0000-0003-1764-5529

IIProfessor Associado na Universidade Estadual de Maringá. E-mail: claudivanlopes@gmail.com ORCID: https://orcid.org/0000-0002$\underline{8479-5095}$ 
colaborativa (DESGAGNÉ, 2007), ou seja, foi realizada com a decisiva parceria de professores que atuam nesse nível de ensino.

Tem-se por pressuposto que o conceito de paisagem, assim como os demais conceitos que estruturam o sistema lógico-conceitual da ciência geográfica, é essencial aos estudos nesse campo e impulsionador da compreensão dos fenômenos espaciais em toda sua complexidade. É pelo uso ordenado dos conceitos de sua ciência que geógrafo vê e analisa o mundo e isso, considerando evidentemente o nível de desenvolvimento cognitivo do aluno e as funções educativas mais gerais desta instituição não é diferente na escola e, especificamente, neste nível de ensino (Fundamental II).

O artigo está estruturado em quatro tópicos: o primeiro destina-se à apresentação das bases teóricas que orientaram o desenvolvimento desse trabalho; 0 segundo pontua o processo metodológico da construção da proposta metodológica; o terceiro apresenta a proposta metodológica juntamente com os resultados obtidos por meio de sua implementação; o quarto apresenta as conclusões realizadas com base na prática pedagógica.

Ao entregar esse texto à apreciação crítica dos leitores, espera-se que ele lhes desperte ideias e um novo olhar sobre a paisagem no ensino de Geografia e que, a partir desse olhar, surjam novas perspectivas considerando este conceito tão valoroso para a ciência geográfica. Espera-se ainda que o conhecimento aqui produzido entre nas salas de aula e contribua para a formação geográfica de valores humanos, inspirando o desenvolvimento de cidadãos críticos e reflexivos de sua própria vivência.

\section{O CONCEITO DE PAISAGEM COMO CAMINHO METODOLÓgICO}

Por ser um termo polissêmico, o conceito de paisagem tem diversas interpretações, de acordo com a teoria por trás do olhar. Para Besse (2014), isso acontece, em parte, devido à atomização profissional e acadêmica das disciplinas que se utilizam do conceito em seu campo de estudos, sendo o mesmo, não apenas um objeto do paisagista, do arquiteto ou do jardineiro, mas também dos cientistas de diversas ciências, como a Antropologia, a Sociologia, a Teoria Literária, a Geografia, entre outras. 
Por meio de diversas perspectivas analíticas, de expressão humana e física, a paisagem ganha espaço nas pesquisas geográficas como um conceito integrador, por trazer interações entre os elementos do mundo físico com os grupos humanos em uma dada área (SALGUEIRO, 2001). Logo, um conceito importante dentro do desenvolvimento da ciência geográfica.

O conceito científico de paisagem é normalmente apresentado aos estudantes do Ensino Fundamental II no início do $6^{\circ}$ ano. Neste momento, o aluno está em fase de transição, não somente de um ciclo escolar para outro, mas também em seu desenvolvimento cognitivo, o que requer uma proposição didática que considere esses fatores como um importante ponto no processo ensino-aprendizagem, uma vez que compreender o espaço geográfico é compreender o mundo onde se está inserido.

Dessa maneira, concorda-se com Busquets (2011) quando afirma que a análise geográfica, baseado na leitura e interpretação das relações estabelecidas entre o natural e o humano, proporciona um método científico de interpretação da paisagem que se mostra muito eficaz no cumprimento dos objetivos da aprendizagem. Por meio da análise geográfica, pode-se proporcionar ao aluno o desenvolvimento das habilidades de observar, descrever, analisar e imaginar paisagens, isto é, o exercício de procedimentos e habilidades que fazem parte dos modos próprios ou específicos da ciência geográfica. Segundo Callai (2003), em contato com tradições geográficas basilares, o aluno se transforma em um investigador do próprio mundo, tendo, assim, condições de formar o raciocínio geográfico. Para a autora, esse raciocínio só fará sentido para ele se for como um processo que pata dele e nele se desenvolva.

Por ser a Geografia uma disciplina de reflexão de identidades individuais e coletivas, Roux (2001) entende a observação e a interpretação da paisagem como tradição e herança da ciência geográfica permanecendo como um instrumento de interrogação epistemológica. Portanto, na perspectiva da autora, a Geografia é uma disciplina de iniciação às ciências sociais, pois suas práticas revelam a relação social, cultural, intelectual, patrimonial e cívica, citadas por ela como resgate da ciência matriz.

A respeito da importância do estudo da paisagem no ensino de Geografia é relevante destacar a possibilidade do desvelamento da naturalidade imposta pelo viver irrefletido do cotidiano. Além disso, o estudo orientado da paisagem permite um melhor conhecimento da paisagem local, contribui para aprofundar a relação de identidade dos alunos com o lugar e para alargar o sentimento de pertencimento (CASTIGLIONE, 2012). 
Cabe ao professor, mediador deste processo, o papel de despertar no aluno o olhar crítico e investigativo sobre essa aparente naturalidade. Também é importante que o professor esteja ciente da natureza dupla da paisagem, pois, como afirma Castiglioni (2011), a educação na paisagem implica trabalhar com duas dimensões simultaneamente: uma é a sensibilidade do olhar (dimensões ocultas a serem interpretadas), e a outra é o raciocínio lógico (ponto de partida da interpretação).

Quando se trata da interpretação da paisagem, vale lembrar que a face oculta que escapa do olhar vai sendo desvelada por meio da interpretação da inteligência perceptiva que se faz presente no olhar geográfico. À medida que a parte visível do objeto é relacionada à sua dimensão oculta, há o entendimento total da forma. Desse modo, "a 'parte' de uma área que observo como paisagem", argumenta Collot (1990, p. 24), "[...] nunca é considerada como absolutamente isolada; eu a percebo precisamente como 'parte' de um espaço vasto que me cabe descobrir viajando ou pedindo ajuda a outra pessoa sobre ela". A paisagem, quando observada, oferece ao observador apenas uma parte ou um aspecto das feições da área devido a dois fatores: a posição de quem observa e o relevo da área observada, manifestando-se de duas maneiras: o horizonte externo e o interno. O primeiro constitui a linha do visível, e o segundo são as partes integrantes dessa linha, mas que se mantêm invisíveis (COLLOT, 1990).

A fim de contribuir para este desvelamento, é preciso distinguir o conceito de 'educação na paisagem' e o conceito de 'paisagem na educação' (BUSQUETS, 2011), pois o primeiro vai além de um componente de aprendizagem e currículo de Geografia. Por conter atributos de dimensão cidadã e ética, a 'educação na paisagem' tem o intuito de colocar o aluno em contato direto com o objeto de estudo. Mais do que somente abordar um conteúdo, busca-se propiciar uma experiência.

Desvelando a aparente naturalidade da paisagem, muda-se o que Gomes (2013) nomeia de regime de visibilidade. Para o autor, trata-se do nível de interesse despertado pela vista da paisagem, provocando diferença na maneira que será interpretada. Há uma grande diferença entre olhar e ver, e isso se deve ao fato de que o olhar dirige o foco e constrói o campo de visão, enquanto ver concede a atenção, o notar, o perceber, o individualizar coisas dentro do campo de visão do olhar (GOMES, 2013). Portanto, para Gomes (2013, p.32), a visibilidade "[...] é sempre desigual, e a atenção é capturada por algo que desperta o interesse." 
A leitura de textos selecionados, que abordem conceitos trabalhados nos conteúdos escolares, coloca os alunos em contato com a realidade pelas palavras, e, segundo o autor, isso está relacionado com conhecimentos de fora de sala de aula, do mundo. Essa proposta didática se torna ainda mais fortalecida quando realizada em conjunto com o trabalho de campo. Nessa proposta, trabalha-se com a imaginação geográfica da criança, ela formará uma rede de vivências informais que ajudam na construção do conceito. Um exemplo é a narração da paisagem proposta por García de La Vega (2016), a qual consiste na utilização de textos narrativos para analisar, associar e estruturar os conteúdos relacionados à paisagem e, a partir daí, extrair os conceitos geográficos. Para o autor, os relatos de viagem e as descrições da paisagem são documentos importantes no ensino de diferentes conceitos geográficos.

Ademais, outro aspecto abordado na idealização da proposta metodológica está relacionado à construção de conceitos, mais especificamente o de paisagem. Para Vygotsky (1993; 2001), existem dois tipos de conceitos: os "conceitos espontâneos" e os "não-espontâneos". Os processos de formação desses conceitos são afetados por diferentes condições, tanto internas quanto externas, mas que essencialmente é único e não conflituoso, contribuindo no desenvolvimento cognitivo do aluno.

Cavalcanti (2005) comenta a trajetória percorrida por estes conceitos, caracterizando-os no processo de formação como "ascendente" e "descendente". Para a autora, os conceitos cotidianos, ascendentes, surgem impregnados de experiência e de forma não-consciente, ascendendo para um conceito consciente. Por sua vez, os conceitos não-espontâneos, também chamados de científicos, surgem de uma definição verbal de aplicação não espontânea e, em um movimento descendente, adquire nível de concretude e experiência. Sendo assim, dois aspectos são bastante relevantes e devem ser levados em conta em sua formação: os processos cotidianos e a instrução formal do aluno via sala de aula.

É importante pontuar o papel do ensino escolar na introdução de conceitos científicos e na busca de sua apropriação pelo aluno, pois, para Cavalcanti (2005), é dessa maneira que se desdobra a possibilidade do processo de generalização que, para a autora, é fundamental para o pensamento conceitual. Além da introdução de conceitos científicos, a valorização e o desenvolvimento dos conceitos cotidianos são de extrema importância na evolução cognitiva dos alunos. Como afirma Vygotsky (1993, p. 93), "É preciso que o desenvolvimento de um conceito espontâneo tenha alcançado um certo 
nível para que a criança possa absorver um conceito científico correlato". Por esse motivo, o desenvolvimento conceitual promovido pelo ambiente escolar, em especial pelo professor, contribui para a consciência reflexiva do aluno e para sua relação com o mundo.

Vygotsky (1993) afirma ainda, que o aprendizado é uma das principais fontes de conceito para a criança em idade escolar, o que reforça a ideia do papel fundamental da escola. Além disso, para ele, esse aprendizado é uma poderosa força no direcionamento do desenvolvimento do aluno, definindo o destino de todo seu desenvolvimento mental. Entretanto o autor alerta quanto ao perigo do ensino do conceito pelo conceito, pois isso faz que o aluno assimile pura e simplesmente um verbalismo desconexo, como um conhecimento isolado do mundo, porque o aluno imita aquilo que Ihe foi dito, mas não faz conexões com a ciência (VYGOTSKY, 2001).

Faz-se necessária a transmissão desse conhecimento conceitual como um elemento estrutural da ciência ensinada, introduzindo-o dentro de uma rede fundamentada por sua epistemologia. No caso da Geografia, os conceitos basilares dão suporte ao ensino dos conteúdos, que são ferramentas do aluno na construção do modo de pensar e analisar a realidade do ponto de vista geográfico, formando sua própria rede conceitual.

O aluno deve formar cognitivamente conceitos geográficos abrangentes que lhe propiciarão ferramentas para a compreensão de sua vida cotidiana e, nesse processo, a didática da Geografia desempenha um papel fundamental (LIBÂNEO 2013; 2015). Para Sacramento (2010), pensar a didática da Geografia é organizar saberes geográficos em articulação com os saberes pedagógicos, relacionando-os, ainda, com o saber do professor, do aluno e o saber escolar, ou seja, a didática da Geografia está nos saberes geográficos, nas particularidades metodológicas e investigativas desenvolvidas ao longo do tempo pela ciência geográfica como também no saber vivencial do professor, do aluno e do contexto escolar.

Sendo assim, ao utilizar a leitura da paisagem sob a perspectiva geográfica para analisar os conteúdos propostos em seu plano de ensino, o professor proporciona ao aluno a apropriação e exercício do método de observação, descrição e reflexão dos geógrafos que iniciaram essa prática e, dessa forma, permite-lhe entrar em contato com o conceito nuclear da ciência matriz. O que se busca com a didática da Geografia é a reflexão sobre a construção da cidadania do aluno guiada pela disciplina, propiciando a 
ele uma articulação entre os aspectos teóricos e práticos ou, como afirma Sacramento (2012), para fazer que ele tenha consciência geográfica sobre seu espaço vivido, fazendo a leitura do mundo por meio das paisagens em diferentes escalas.

\section{METODOLOGIA}

Considerando as possibilidades de potencializar a utilização do conceito de paisagem no ensino de Geografia, investiu-se um conceito carregado de significações que, se utilizado adequada e didaticamente, pode oferecer um ambiente de aprendizagem favorável. Concorda-se com Cavalcanti (2013, p. 21) quando afirma que "[...] a seleção da paisagem geográfica como eixo para abordar os conteúdos escolares tem a ver com a compreensão de que aprender tal conceito ajuda as pessoas a verem melhor o mundo". Portanto a apropriação do conceito de paisagem pelo aluno - não tomado em si mesmo, mas como um instrumento teórico de leitura do espaço geográfico - possibilita-lhe desenvolver gradativamente um olhar geográfico do mundo e, particularmente, sobre sua própria vivência.

Para alcançar o objetivo de pensar uma metodologia que propiciasse ao aluno aprendizagem dos conteúdos escolares por meio da utilização do conceito de paisagem, pautou-se na perspectiva das pesquisas qualitativas (BAUER; GASKELL, 2002; CHIZZOTTI, 2008). No interior dessa perspectiva, optou-se por situá-la no âmbito das pesquisas ativas (CHIZZOTTI, 2008) e, mais especificamente, na abordagem colaborativa da pesquisa ativa em educação (DESGAGNÉ, 2007).

Para Chizzotti (2008), as pesquisas ativas pressupõem, de modo geral, a tomada consciência dos problemas e fatos próprios determinantes de sua realidade, por parte tanto dos investigadores como dos investigados, e a partir disso, formular meios para superá-los. No âmbito da educação, a abordagem que envolve as contribuições dos professores em exercício no processo de investigação é chamada por Desgagné (2007) de colaborativa. Para a autora, no decorrer dessas pesquisas, tais professores tornam-se "co-construtores" do conhecimento produzido, o que contribui para a estruturação de pesquisas que valorizem a compreensão que o professor tem das práticas que desenvolve.

Assim, nesta investigação, segundo os pressupostos teóricos apresentados, duas professoras da rede básica de ensino do Núcleo Regional de Maringá (NRE/MARINGÁ) foram convidadas a participar colaborativamente na pesquisa. Trata-se de professoras que têm ampla experiência no ensino e que, reconhecidas por seus pares, apresentam 
um Conhecimento Pedagógico Geográfico (CPG) estabelecido e bem desenvolvido (SHULMAN, 2014; LOPES; PONTUSCHKA, 2015). Pensou-se que, ao contar com a colaboração de profissionais que participam ativamente do processo de ensinoaprendizagem em pleno exercício de sua profissão, obter-se-ia maior sucesso na construção da metodologia que, por meio do presente artigo, poderá ser socializada e, como se deseja, utilizada por seus pares.

Após a implementação, para averiguar os resultados, foram analisadas, além das vivências empíricas do processo, as respostas dos alunos nos guias de leitura da paisagem. Com base no objetivo principal de desenvolver uma proposta metodológica que, além da apreensão do conteúdo, propicie ao aluno o desenvolvimento do conceito científico de paisagem, como também lhe permita acessar suas dimensões ocultas, a fim de perceber seu "eu transformador" no ambiente, três principais hipóteses surgiram com intuito de verificar tal objetivo foi atingido, sintetizadas nas seguintes questões: 1. Houve desenvolvimento do conceito espontâneo a fim da apreensão do conceito científico?; 2. Os alunos acessam as dimensões ocultas da paisagem por intermédio da percepção?; 3. Os alunos se colocam como transformadores da paisagem? Estas foram validadas ou refutadas por meio da análise das respostas dadas no guia de leitura da paisagem ao final de sua implementação.

\section{RESULTADOS E DISCUSSÕES}

Como fruto do referencial bibliográfico apresentado e da relação colaborativa com as professoras convidadas, foi desenvolvida uma metodologia de leitura da paisagem geográfica considerando a paisagem como um caminho para desenvolver distintas capacidades cognitivas, como a atenção, a observação, a memória, 0 julgamento e o raciocínio, utilizando-se em sua consecução o conceito. Reafirma-se, nesse momento, que o objetivo da metodologia é demonstrar as possibilidades de trabalhar os diversos conteúdos da Geografia escolar, tendo como eixo norteador o estudo da paisagem sem, contudo, prender-se ao ensino do conceito propriamente. É importante salientar que as etapas definidas na metodologia não são fixas, prontas e acabadas. Cabe ao professor, então, livremente e com base em seus conhecimentos, utilizá-la como tal ou adaptá-la à sua realidade. Espera-se dele, portanto, uma recepção criativa, utilizando-se da metodologia no processo de apropriação do conhecimento pelo aluno. 
Quadro 1 - Sistematização das etapas da proposta metodológica

\begin{tabular}{|c|c|c|c|c|c|}
\hline ETAPA & SUBETAPA & O QUE É FEITO? & $\begin{array}{c}\text { QUEM } \\
\text { REALIZA? }\end{array}$ & ONDE? & TEMPO \\
\hline \multirow{3}{*}{$\begin{array}{l}\text { Planejamento } \\
\text { Didático }\end{array}$} & $\begin{array}{l}\text { 1. Escolha da } \\
\text { temática de } \\
\text { estudo }\end{array}$ & $\begin{array}{l}\text { Nesta etapa, deve-se } \\
\text { escolher a temática de } \\
\text { estudo com base no } \\
\text { conteúdo trabalhado, } \\
\text { considerando que a } \\
\text { metodologia de leitura } \\
\text { da paisagem geográfica } \\
\text { proposta é um recurso } \\
\text { didático e não } \\
\text { necessariamente um } \\
\text { conteúdo. }\end{array}$ & $\begin{array}{l}\text { Professora e } \\
\text { Mestranda }\end{array}$ & Escola & \multirow[b]{2}{*}{$1 \mathrm{~h} / \mathrm{a}$} \\
\hline & $\begin{array}{l}\text { 2.Definição dos } \\
\text { objetivos de } \\
\text { aprendizagem }\end{array}$ & $\begin{array}{l}\text { Nesta etapa, organizam- } \\
\text { se os objetivos } \\
\text { pedagógicos a serem } \\
\text { alcançados e define-se } \\
\text { que conhecimentos } \\
\text { serão, como meta, } \\
\text { adquiridos pelos alunos. } \\
\text { Esses objetivos devem } \\
\text { estar intimamente } \\
\text { relacionados ao } \\
\text { conteúdo que se } \\
\text { pretende estudar pela } \\
\text { leitura da paisagem. }\end{array}$ & $\begin{array}{l}\text { Professora e } \\
\text { Mestranda }\end{array}$ & Escola & \\
\hline & $\begin{array}{l}\text { 3.Produção do } \\
\text { material }\end{array}$ & $\begin{array}{c}\text { Essa etapa contempla a } \\
\text { produção dos materiais } \\
\text { a serem utilizados } \\
\text { durante o } \\
\text { desenvolvimento da } \\
\text { metodologia. A } \\
\text { implementação da } \\
\text { metodologia exige a } \\
\text { construção de um guia } \\
\text { de leitura da paisagem, } \\
\text { que não será utilizado } \\
\text { na análise e na coleta } \\
\text { de dados no trabalho de } \\
\text { campo e também em } \\
\text { sala. } \\
\end{array}$ & $\begin{array}{l}\text { Professora e } \\
\text { Mestranda }\end{array}$ & Escola & $2 \mathrm{~h} / \mathrm{a}$ \\
\hline Desenvolvimento & $\begin{array}{l}\text { 1.Aprofundamen } \\
\text { to conceitual }\end{array}$ & $\begin{array}{c}\text { Recapitulação do } \\
\text { conceito de paisagem na } \\
\text { Geografia, considerando } \\
\text { os aportes teóricos } \\
\text { utilizados no projeto. } \\
\text { Além disso, trabalha-se } \\
\text { um relato de paisagem; } \\
\text { após sua leitura, } \\
\text { requisita-se aos alunos } \\
\text { que produzam desenhos } \\
\text { com base no relato que } \\
\text { ouviram. }\end{array}$ & $\begin{array}{l}\text { Professora, } \\
\text { mestranda e } \\
\text { alunos }\end{array}$ & $\begin{array}{l}\text { Sala de } \\
\text { aula }\end{array}$ & $1 \mathrm{~h} / \mathrm{a}$ \\
\hline
\end{tabular}




\begin{tabular}{|c|c|c|c|c|c|}
\hline ETAPA & SUBETAPA & O QUE É FEITO? & $\begin{array}{c}\text { QUEM } \\
\text { REALIZA? }\end{array}$ & ONDE? & TEMPO \\
\hline \multirow[b]{2}{*}{ Desenvolvimento } & $\begin{array}{l}\text { 2. Leitura } \\
\text { indireta da } \\
\text { paisagem }\end{array}$ & $\begin{array}{l}\text { Neste momento, é feita } \\
\text { a análise indireta de } \\
\text { paisagens relacionada } \\
\text { ao conteúdo a ser } \\
\text { ensinado. Para essa } \\
\text { análise, utiliza-se uma } \\
\text { tabela contida no guia } \\
\text { de leitura. }\end{array}$ & $\begin{array}{l}\text { Professora, } \\
\text { mestranda e } \\
\text { alunos }\end{array}$ & $\begin{array}{l}\text { Sala de } \\
\text { aula }\end{array}$ & $1 \mathrm{~h} / \mathrm{a}$ \\
\hline & $\begin{array}{l}\text { 3. Leitura direta } \\
\text { da paisagem }\end{array}$ & $\begin{array}{l}\text { Neste momento, dá-se } \\
\text { início à leitura direta, } \\
\text { quando se realiza uma } \\
\text { aula de campo, } \\
\text { intitulada "expedição } \\
\text { geográfica". Para a } \\
\text { análise daquilo que é } \\
\text { visto, utiliza-se, } \\
\text { também, uma tabela } \\
\text { contida no guia de } \\
\text { leitura. }\end{array}$ & $\begin{array}{l}\text { Professora, } \\
\text { alunos e } \\
\text { equipe } \\
\text { pedagógica }\end{array}$ & $\begin{array}{l}\text { Arredores } \\
\text { do } \\
\text { colégio/ } \\
\text { paisagem } \\
\text { cotidiana }\end{array}$ & $2 \mathrm{~h} / \mathrm{a}$ \\
\hline $\begin{array}{l}\text { Discussão e } \\
\text { análise } \\
\text { dos dados }\end{array}$ & - & $\begin{array}{l}\text { Essa etapa é realizada } \\
\text { na volta para a sala de } \\
\text { aula. Após a Expedição } \\
\text { geográfica, é feito um } \\
\text { debate sobre os dados } \\
\text { coletados: fotos, } \\
\text { anotações, desenhos. } \\
\text { Para esse debate os } \\
\text { guias de leitura serão } \\
\text { recolhidos e as } \\
\text { perguntas norteadoras } \\
\text { serão desenvolvidas } \\
\text { com base nas anotações } \\
\text { dos alunos. }\end{array}$ & $\begin{array}{l}\text { Professora e } \\
\text { Mestranda }\end{array}$ & $\begin{array}{l}\text { Sala de } \\
\text { aula }\end{array}$ & $1 \mathrm{~h} / \mathrm{a}$ \\
\hline Compartilhamento & - & $\begin{array}{c}\text { Nesta etapa, } \\
\text { desenvolve-se um mural } \\
\text { com anotações, fotos, } \\
\text { desenhos e conceitos de } \\
\text { paisagem, elaborado } \\
\text { pelos alunos a ser } \\
\text { compartilhado para a } \\
\text { comunidade escolar. }\end{array}$ & $\begin{array}{l}\text { Professora, } \\
\text { mestranda e } \\
\text { alunos }\end{array}$ & $\begin{array}{c}\text { Sala de } \\
\text { aula }\end{array}$ & $2 \mathrm{~h} / \mathrm{a}$ \\
\hline $\begin{array}{l}\text { Avaliação dos } \\
\text { resultados }\end{array}$ & - & $\begin{array}{c}\text { Neste momento, são } \\
\text { analisados os objetivos } \\
\text { propostos no início da } \\
\text { implementação para } \\
\text { avaliar as conquistas } \\
\text { feitas pela sala, como } \\
\text { também a análise por } \\
\text { parte da professora e da } \\
\text { mestranda sobre a } \\
\text { proposta metodológica } \\
\text { toda, a fim de identificar } \\
\text { possíveis pontos de } \\
\text { melhoria. }\end{array}$ & $\begin{array}{l}\text { Professora e } \\
\text { Mestranda }\end{array}$ & & $1 \mathrm{~h} / \mathrm{a}$ \\
\hline
\end{tabular}


A metodologia (quadro 1) consiste em cinco etapas. A primeira é a etapa de planejamento, que envolve a disposição dos planos e materiais que darão sustentação à metodologia, ao guia de leitura da paisagem (APÊNDICE A), além dos objetivos de aprendizagem que serão discutidos entre professor e aluno. A segunda é a etapa de desenvolvimento, que envolve a implementação da metodologia propriamente dita e seu passo a passo, colocando em ação os planos da etapa anterior, que envolverá uma leitura direta e indireta da paisagem.

A terceira é a etapa de discussão e análise dos dados, que envolve a discussão pós-expedição e recolhimento de dados, que acontecerá em sala aula entre professor e aluno. Nessa etapa, os alunos escolherão quais de suas produções serão partilhadas com a comunidade escolar, tema da próxima etapa. A quarta é a etapa de compartilhamento e divulgação dos resultados, na qual o material produzido será partilhado com a comunidade escolar por meio de um painel. E a quinta e última é a etapa de avaliação dos resultados conquistados, sendo necessária a revisão dos objetivos propostos na primeira etapa.

A implementação da proposta metodológica de leitura da paisagem foi realizada em duas escolas da rede estadual de ensino do Núcleo Regional de Educação de Maringá, Paraná, sendo uma, na cidade polo do referido núcleo (Maringá) e outra na cidade de Sarandi. Nessas escolas, estão lotadas, respectivamente, as professoras colaboradoras Catarina e Helena'. Para a turma da professora Catarina, um $6 .^{\circ}$ ano, foi escolhido o tema "A interferência humana na paisagem", pois a professora Catarina estava trabalhando temas sobre industrialização, extrativismo e agropecuária no país. Para a turma da professora Helena, um $7 .^{\circ}$ ano, o tema escolhido foi "As marcas da desigualdade social na paisagem", porque ela estava trabalhando o conteúdo acerca da desigualdade social no Brasil.

Para observar o atual nível de abstração e possibilidade de generalização contido na apreensão do conceito pelos alunos das duas turmas, que surge impregnado de experiências de uma forma ainda não-consciente (CAVALCANTI, 2005), e ter um ponto de partida para detectar o processo de "ascendência", foi solicitado inicialmente que os alunos respondessem à seguinte questão: "Para você, o que é paisagem? ", contida no guia de leitura da paisagem. Mediante as respostas apresentadas, ao final da implementação, momento em que foi repetida a pergunta aos alunos, pode-se validar ou refutar a hipótese acerca da contribuição positiva dada à construção do conceito por meio da proposta metodológica. 
Após, seguindo com o resgate teórico do conceito de paisagem, foi trabalhado o regime de visibilidade (GOMES, 2013) com os alunos, mediante o exercício da narração da paisagem (GARCIA DE LA VEGA, 2016). A atividade teve como objetivo despertar o regime de significação contido nas paisagens cotidianas, pois, pensando a visibilidade como informante daquilo que pode ser considerado importante e o porquê dessa avaliação, quis-se atingir a reflexão do aluno sobre o que se vê, como também sobre o que não se vê (GOMES, 2013).

Narrou-se um passeio por uma paisagem conhecida dos alunos, bem próxima à escola onde estudam e, em seguida, foi-lhes pedido que desenhassem aquela paisagem. Por meio da análise e interpretação dos desenhos (Figuras 1 e 2), pode-se perceber que alguns dos alunos foram além daquilo que Ihes foi narrado, como, por exemplo, a aluna Olívia, que representou o salão paroquial, mesmo este não sendo citado na narração. Os alunos elegeram aquilo que thes é mais importante para ser representado, o que corrobora as ideias de Gomes (2013), quando afirma existir uma Geografia no olhar que, ao selecionar o que deve ser lembrado ou esquecido, realiza uma interpretação geográfica pautada em "[...] procedimentos regulares, que estabelecem socialmente aquilo que deve ser visto, as condições e os valores que devem ser julgados" (GOMES, 2013, p. 52). Ao realizar a atividade, o aluno pôde exercitar seu olhar geográfico, selecionando elementos que Ihes são significativos cultural e socialmente.

\section{Figura 1 - Desenhos da turma da professora Helena}

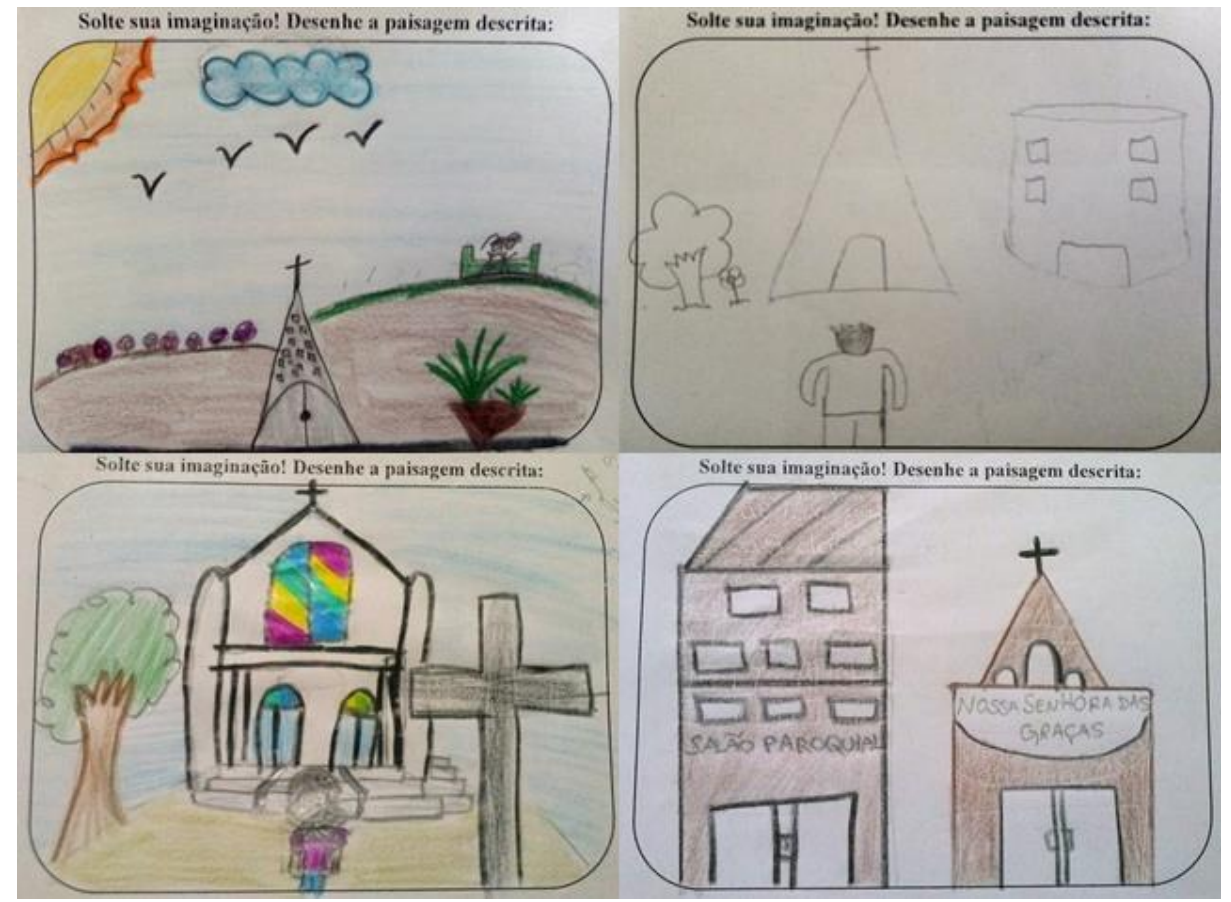

Fonte: Acervo particular dos autores. 
Figura 2 - Desenhos da turma da professora Catarina

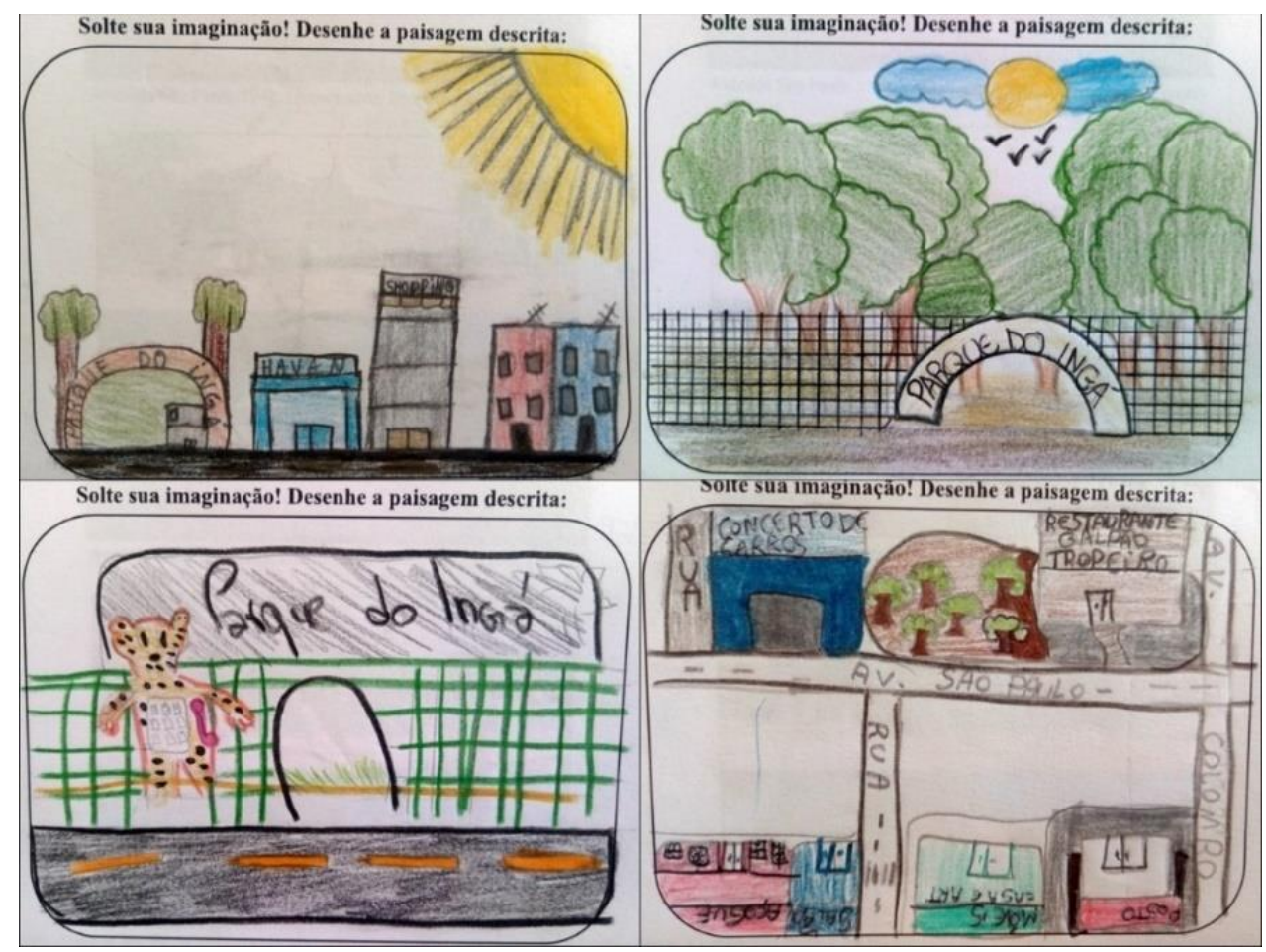

Fonte: Acervo particular dos autores.

Em seguida, deu-se início à subetapa de leitura indireta da paisagem. Esta foi realizada por meio da análise de imagens (Figuras 3, 4, 5 e 6) relacionadas ao tema escolhido para pautar a implementação dos projetos.

Figura 3 - Leitura indireta da paisagem: turma da professora Helena

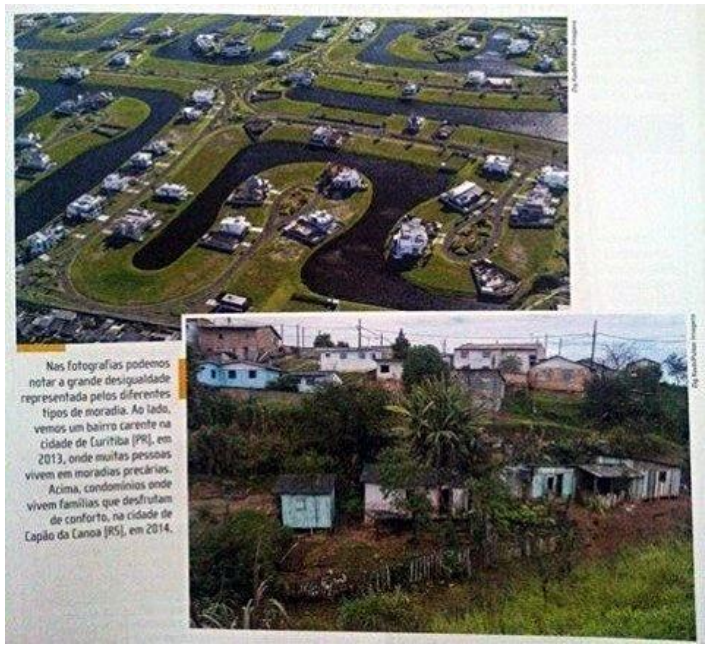

Fonte: Adas e Adas (2015). 
Figura 4 - Leitura indireta da paisagem: turma da professora Catarina. Maringá (1948)

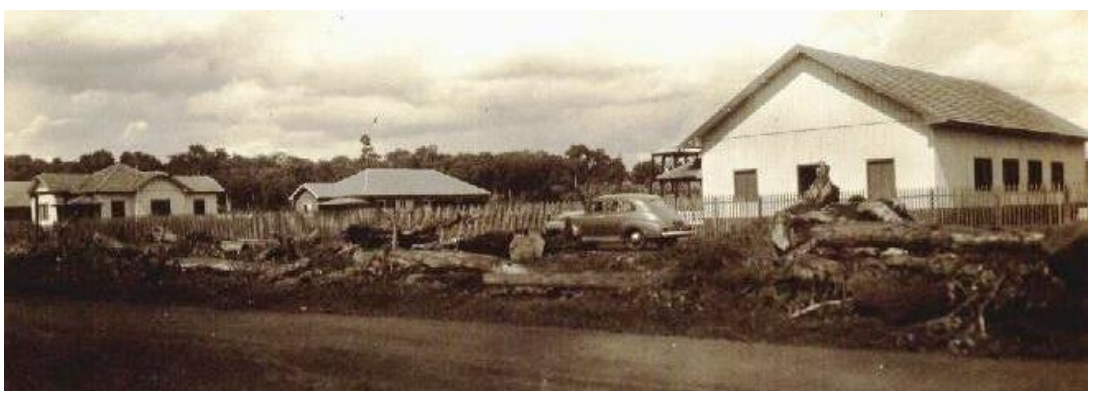

Fonte: www.maringahistorica.com.br.

Figura 5 - Leitura indireta da paisagem: turma da professora Catarina. Maringá (1975)

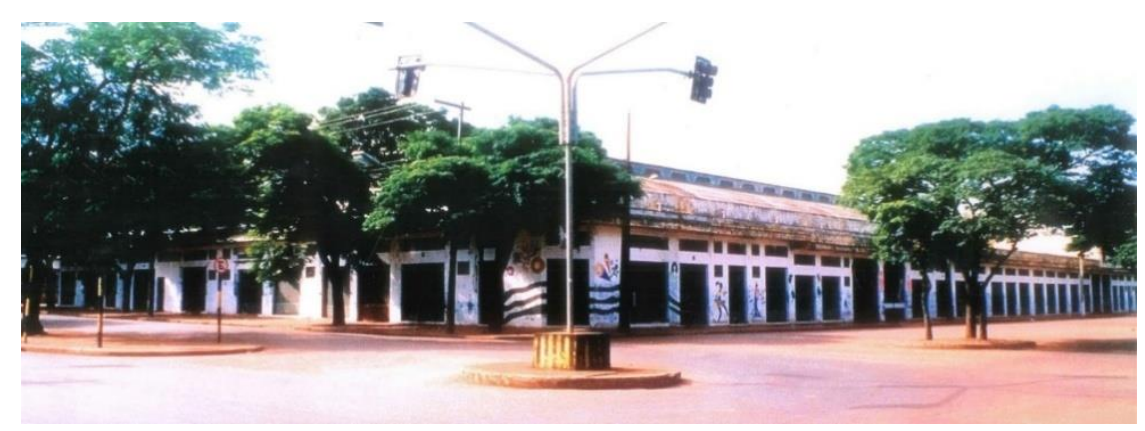

Fonte: www.maringahistorica.com.br.

Figura 6 - Leitura indireta da paisagem: turma da professora Catarina. Maringá (1989)

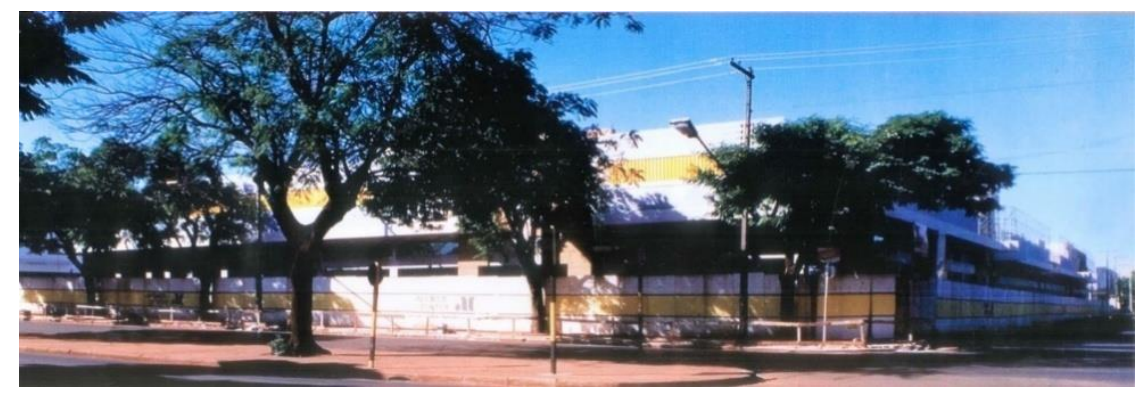

Fonte: www.maringahistorica.com.br.

Na turma da professora Helena, foram utilizadas imagens contidas no livro didático utilizado pela turma (ADAS; ADAS, 2015); na turma da professora Catarina, como o trabalho de leitura indireta teve como foco a análise das intervenções humanas, foram utilizadas imagens de uma mesma paisagem em diferentes momentos históricos. A atividade teve como objetivo ambientar os alunos com a análise geográfica. Pautando-se na proposição de Monbeig (1954) de complexos geográficos, buscou-se, nesse momento, conduzir os alunos pelo caminho da reflexão 
das "parcelas apreciáveis" não visíveis, que se encontram implícitas nos elementos físicos e naturais que compõem as paisagens.

Por meio dessa atividade, pode-se perceber que os alunos, tanto da turma da professora Helena, como da professora Catarina, puderam analisar geograficamente as imagens. Tal afirmação é corroborada pelas respostas dadas pelos alunos em seus guias de leitura da paisagem. Na turma da professora Helena, foram frequentes respostas como a do aluno Leandro: "Sim, eu mudaria a paisagem de cima [condomínio], eu iria tirar 90\% dela e iria fazer muitas coisas para a paisagem de baixo [comunidade]"; do Natan: "eu quebraria o muro envolta da paisagem de cima [condomínio] para os moradores que necessitam"; ou do Gabriel: "não tem saneamento básico e as casas são de madeira [na comunidade]". Enquanto isso, na turma da professora Catarina, foram frequentes respostas como a do Marcos: "Os elementos estão no mesmo lugar, com o tempo mudou a paisagem"; do Eliton: "O tempo é a ligação, todos os elementos foram modificados através dele, até as arvores"; do Iran: "Os elementos estão tudo [sic] no mesmo lugar, só que com o tempo foi se modificando a paisagem", e do Fernando: "é o mesmo lugar, todos eles foram modificados pelo tempo".

$\mathrm{Na}$ aula seguinte, iniciou-se a atividade de leitura direta da paisagem, a chamada Expedição Geográfica. Nas duas turmas, foi realizada a exploração de um percurso de 4 pontos pela paisagem cotidiana. Essa subetapa embasou-se no conceito de educação na paisagem, proposto por Busquets (2011), no qual, pelo ato de ir a campo e experimentar o meio, o aluno se coloca na presença do objeto de estudo, desenvolvendo seu olhar geográfico in loco. Durante o contato do mundo com o ponto de vista mediado pela educação na paisagem experimentada na Expedição Geográfica, alguns detalhes são perdidos devido a fatores que vão desde a posição do observador até as condições climáticas do dia. Dessa maneira, a paisagem mantém uma face oculta que é preenchida pela percepção (COLLOT, 1990). Buscouse preencher essas lacunas por meio do raciocínio geográfico, propiciando aos alunos o exercício de reflexão resguardado pelo embasamento teórico-científico.

Ainda que se tenha identificado limitações, considera-se que o conjunto das atividades que compõem a subetapa de leitura direta da paisagem relevaram-se adequadas ao processo de ensino e aprendizagem, pois, por meio dessas atividades, foi possível proporcionar aos alunos o exercício da observação, descrição e reflexão 
de sua vivência. Este exercício, quando organizado a partir da articulação dos saberes geográficos com os saberes pedagógicos, caracterizam a didática da Geografia (SACRAMENTO, 2012), sendo este o objetivo maior no desenvolvimento da proposta metodológica.

Ao final da implementação, com intuito de verificar a evolução da compreensão do conceito de paisagem espontâneo dos alunos, foi repetida a questão "Para você, o que é paisagem?". Os resultados podem ser conferidos no quadro n. 2.

\section{Quadro 2 - Evolução conceitual}

\begin{tabular}{|c|c|c|c|}
\hline Aluno (a) & Turma & $\begin{array}{c}\text { Resposta no início da } \\
\text { implementação }\end{array}$ & Resposta no final da implementação \\
\hline Alice & $\begin{array}{l}\text { Professora } \\
\text { Catarina }\end{array}$ & "Paisagem bonita." & "Cheiro, cores, sentimentos, movimento." \\
\hline Camila & $\begin{array}{l}\text { Professora } \\
\text { Catarina }\end{array}$ & "Lugar bonito." & $\begin{array}{l}\text { "Não somente o que se vê, mas } \\
\text { sentimentos e sons." }\end{array}$ \\
\hline Fernando & $\begin{array}{c}\text { Professora } \\
\text { Catarina }\end{array}$ & "Aquilo que vemos." & $\begin{array}{c}\text { "Aquilo que vemos, tocamos e sentimos, } \\
\text { elementos físicos, sentimentos, odores, } \\
\text { modificadas pelo tempo." }\end{array}$ \\
\hline Heron & $\begin{array}{l}\text { Professora } \\
\text { Catarina }\end{array}$ & $\begin{array}{l}\text { "Onde tem elementos } \\
\text { físicos." }\end{array}$ & $\begin{array}{c}\text { "Um lugar onde tem elementos físicos e } \\
\text { também contenha sentimentos através do } \\
\text { tempo." }\end{array}$ \\
\hline Hélio & $\begin{array}{l}\text { Professora } \\
\text { Helena }\end{array}$ & $\begin{array}{l}\text { "Paisagem pra mim é } \\
\text { um bosque de árvores, } \\
\text { belas casas e um } \\
\text { riacho." }\end{array}$ & $\begin{array}{l}\text { "Paisagem não é só aquilo que é bonito, } \\
\text { não é só aquilo a gente vê, é o que } \\
\text { sentimos e o que refletimos." }\end{array}$ \\
\hline Leandro & $\begin{array}{l}\text { Professora } \\
\text { Helena }\end{array}$ & $\begin{array}{c}\text { "Para mim a paisagem é } \\
\text { um lugar bonito cheio } \\
\text { de flores." }\end{array}$ & $\begin{array}{l}\text { "Paisagem é algo que você vê e sente, mas } \\
\text { não só aquilo que você gosta. É como uma } \\
\text { rua com animais, flores, fumaça, carros, } \\
\text { juntando tudo se forma a paisagem." }\end{array}$ \\
\hline Pedro & $\begin{array}{l}\text { Professora } \\
\text { Helena }\end{array}$ & $\begin{array}{c}\text { "Tudo aquilo que é } \\
\text { bonito, a natureza, } \\
\text { porque foi Deus que } \\
\text { deu" }\end{array}$ & $\begin{array}{l}\text { "Uma coisa que a gente pode ver, sentir e } \\
\text { ouvir, diretamente ou indiretamente." }\end{array}$ \\
\hline Olívia & $\begin{array}{l}\text { Professora } \\
\text { Helena }\end{array}$ & $\begin{array}{l}\text { "É onde nós podemos } \\
\text { apreciar uma paisagem } \\
\text { e natureza" }\end{array}$ & $\begin{array}{l}\text { "Paisagem pode ser vista de duas formas: } \\
\text { Indireta, pelas fotografias, um quadro e } \\
\text { Direta: aquela que estamos presenciando e } \\
\text { vendo a olho nu. Resumindo: tudo que } \\
\text { vemos, sentimos, ouvimos em uma } \\
\text { determinada região." }\end{array}$ \\
\hline
\end{tabular}

Observa-se, na análise das respostas, que, inicialmente, uma percepção mais espontânea do conceito, marcada pelo entendimento veiculado ordinariamente pelo "senso comum", fez os alunos relacioná-lo - como se viu também na análise das falas dos alunos da turma 1 - à beleza cênica de um determinado lugar, cujo órgão do sentido fundamental, senão exclusivo em sua apreensão, é a visão. Têm-se, neste 
caso, uma situação na qual o estudante, tal qual o geógrafo alvo da crítica de Monbeig (1954), satisfaz-se em ser uma "excelente máquina fotográfica", valorizando a simples descrição da paisagem, em prejuízo da análise do processo de sua constituição.

Observou-se, em contrapartida, que a intervenção pedagógica, proposta pela metodologia de leitura da paisagem, permitiu aos alunos uma ampliação na sua compreensão inicial, incorporando à análise aspectos antes "invisíveis", não considerados ou ignorados. Observa-se, nas respostas dos alunos, que eles não rejeitam a importância da visão para a leitura da paisagem - o "olhar", como ponto de partida, permanece -, mas vão além, fazendo referências ao olfato, à audição, ao tato e, remetendo a aspectos relacionados à apreensão subjetiva das paisagens, os sentimentos e as emoções. O "regime da visibilidade", ordinário e cotidiano, assim é enriquecido por um olhar mais atento e refinado; mais especificamente, o olhar é agora conduzido ou governado pela teoria geográfica.

\section{CONCLUSÕES}

Tendo o objetivo principal de apresentar uma proposta metodológica que colabore não só com a construção do conceito de paisagem por alunos do Ensino Fundamenta II, mas também com a apreensão de conteúdos geográficos, na valorização de paisagens cotidianas e no seu desvelamento, conclui-se que a prática pedagógica aqui apresentada cooperou com o ensino-aprendizagem da Geografia no sentido de contribuir para que fosse possível atingir tal objetivo.

A leitura indireta da paisagem propiciou aos alunos o primeiro contato com a metodologia de análise geográfica, revisitando os modos próprios da ciência e desenvolvendo habilidades, tais como a observação, a descrição e a análise indireta, por meio de fotografias e do relato, o que se mostrou um método eficiente na composição do raciocínio geográfico. Percebeu-se o fato, observando os avanços das duas turmas após a atividade, expressos na análise apresentada. Os alunos, de fato, demonstraram a capacidade de interpretar registros imagéticos sem se prenderem à mera descrição dos objetos observados.

A leitura direta da paisagem proporcionou aos alunos o contato mediado com a paisagem cotidiana. Por meio de uma visão teoricamente informada, questionou-se o 
"regime de visibilidade", proporcionando aos alunos a reflexão sobre a aparente naturalidade do espaço vivido, além de desenvolver o sentimento de pertencimento àquela paisagem, criando uma consciência geográfica sobre 0 espaço. Consequentemente, a moldura do olhar cotidiano foi expandida ou ampliada com a incorporação de novos elementos e perspectivas de análise que possibilitaram, complementarmente ao exercício de observação indireta, o desenvolvimento do raciocínio geográfico.

Destacou-se uma apreensão mais subjetiva da paisagem, sem, entretanto, desconsiderar seus aspectos objetivos. Dessa maneira, defende-se que, para além de uma relação de exterioridade, a presença das palavras, "sentimentos", e "movimento" indica uma modificação no modo como os alunos compreendem e se relacionam com a paisagem. Pode-se imaginar que a presença de expressões como "cores", "movimentos", "sentimentos" pode ser a simples repetição de palavras utilizadas pela professora e pela pesquisadora durante as atividades de implementação. No entanto, compreendidas em seu conjunto e relacionadas com toda a proposta metodológica, percebe-se que a utilização dessas palavras foi a maneira encontrada pelos alunos para expressar suas percepções sobre as relações humanas geradoras daquela paisagem, não sendo utilizadas como um simples verbalismo, mas como expressão da interferência humana em sua paisagem cotidiana.

Assim, unidas, leitura direta e indireta, propiciaram aos alunos 0 aprimoramento de suas capacidades intelectuais, 0 que consequentemente, influenciou seu desenvolvimento conceitual. Partindo do conceito espontâneo, os alunos se apropriaram do pensamento teórico-científico da ciência geográfica de maneira didática na proposta metodológica, o que fez que formassem um pensamento mais abrangente e abstrato, propiciando-lhes, como se desejava, a formação de conceitos científicos (CAVALCANTI, 2005).

A paisagem revela-se como um conceito de grande relevância dentro do ensino de Geografia, pois, por meio dela, pode-se propiciar ao aluno, além do contato com a realidade, a possibilidade de refletir e de se colocar como transformador do ambiente. O encontro do mundo com o ponto de vista desperta a percepção, fonte do pensamento reflexivo. Dessa maneira, superam-se os dualismos do visível e do invisível, do sujeito e do objeto, do pensamento e da matéria, da natureza e da 
cultura. A percepção sobre a paisagem institui a interação, convida a pensar de maneira diferente, de maneira conjunta e estruturada, complexa e relacionada.

\section{REFERÊNCIAS}

ADAS, M.; ADAS, S. Expedições geográficas - 70 ano. São Paulo: Moderna, $2^{\circ}$ edição, 2015.

BAUER, M. W.; GASKELL, G. Pesquisa qualitativa com texto, imagem e som: um manual prático. Petrópolis, Vozes, 2002.

BESSE, J. M. 0 gosto do mundo: exercícios de paisagem. Rio de Janeiro. EdUERJ, 2014.

BRASIL. Ministério da Educação. Parâmetros curriculares nacionais: história e geografia. Primeiro e segundos ciclos. Secretaria de Educação Fundamental. Brasília, 1997, 166p.

BUSQUETS, J. La importància de l'educació en paisatge. In: NOGUÉ, J. et al. (Orgs) Paisatge i educació. Observatori del Paisatge de Catalunya. Departament d’Ensenyament de la Generalitat de Catalunya, p.69-88, 2011.

CALLAI, H. C. Do ensinar Geografia ao produzir o pensamento geográfico. In: REGO, N. et al. (Org.). Um pouco do mundo cabe nas mãos. Porto Alegre: Editora da UFRGS, 2003, p. 57-74.

CAMILLONI, A. R. W. Didáctica general y didácticas específicas. In: CAMILLONI, A. R. W. (Org.). El saber didáctico. 1. ed. Buenos Aires: Paidós, 2016. p.23-39.

CASTIGLIONE, B. L'éducation au paysage à l'école. In: Facettes du paysage: réflexions et propositions pour la mise en oeuvre de la Convention européenne du paysage. Conseil de l'Europe. 2012, p. 223-269.

CAVALCANTI, L. S. Cotidiano. Mediação pedagógica e formação de conceitos: uma contribuição de Vygotsky ao ensino de Geografia. Caderno Cedes, Campinas, v.25, n. 66, p. 185-207, 2005.

CHIZZOTTI, A. Pesquisa qualitativa em ciências humanas e sociais. Petrópolis: Editora Vozes, 2008, 144p.

DESGAGNÉ, S. O conceito de pesquisa colaborativa: a ideia de uma aproximação entre pesquisadores universitários e professores práticos. Revista Educação em Questão, Natal, v. 29, n. 15, p. 7-35, 2007. Disponível em: https://periodicos.ufrn.br/educacaoemquestao/article/view/4443. Acesso em: 25 jul. 2017

GARCIA DE LA VEGA, A. La narración del paisaje y su relación com la aquisición de los conceptos geográficos. In: CASTROGIOVANNI, A.C, et al. (Orgs). Movimentos para ensinar Geografia - oscilações. Porto Alegre: Editora Letral I, 2016, p. 17-30.

GOMES, P. C. C. O Lugar do olhar: elementos para uma Geografia da visibilidade. Rio de Janeiro: Bertrand Brasil, 2013, 319p. 
LIBÂNEO, J. C. A teoria do ensino para o desenvolvimento humano e o planejamento de ensino. Educativa, Goiânia, v. 19, n. 2, p. 353-387, 2016

LIBÂNEO, J. C. Antitomias na formação de professores e a busca de integração entre o conhecimento pedagógico-didático e o conhecimento disciplinar. In: MARIN, A.J.; PIMENTA, S. G. Didática: teoria e pesquisa. 1. ed. Araraquara: Junqueira\&Marin, p. 3965, 2015

LIBÂNEO, J. C. Didática. São Paulo: Cortez, 2013, 287p.

LOPES, C.S; PONTUSCHKA, N.N. O conhecimento pedagógico do conteúdo na prática profissional de professores de Geografia. GEOUSP - Espaço e Tempo, São Paulo, v. 19, n. 1, p. $76-92,2015$.

ROUX, A. Enseigner le paysage? Ecole élémentaire, collège, lycée. Caen-FR: Centre Régional de Documentation Pédagogique, 2001. 106p.

SACRAMENTO, A. C. R. Didática e Educação geográfica: algumas notas. Unipluriversidad, Medellín. v. 10, n.3, p. 1-9, 2010. Disponível em: https://aprendeenlinea.udea.edu.co/revistas/index.php/unip/article/viewFile/9581/8821. Acesso em: 7 jun. 2017

SACRAMENTO, A. C. R. A consciência e a mediação: um estudo sobre as didáticas contemporâneas dos professores de Geografia da rede pública de São Paulo e do Rio de Janeiro. 2012, 325p. Tese (Doutorado em Geografia) Programa de Pós-Graduação em Geografia Física, Universidade de São Paulo, São Paulo.

SALGUEIRO, T. B. Paisagem e Geografia. Finisterra, Lisboa, v.36, n.72, p.37-53, 2001.

SHULMAN, L. Conhecimento e ensino: fundamentos para a nova reforma. Cadernos Cenpec. São Paulo, v.4, n.2, p.196-229, 2014.

VYGOTSKY, L. S. Pensamento e linguagem. São Paulo: Martins Fontes, 1993. 135p.

VYGOTSKY, L. S. A construção do pensamento e da linguagem. São Paulo: Martins Fontes, 2001.496p. 


\section{Guia de}

\section{Leitura da Paisagem}

\section{Tema:}

Escola:

Série:

Aluno (a):

\section{1. $O$ conceito de paisagem}

Paisagem é aquilo que vemos e sentimos diante dos nossos olhos Ela não é formada apenas por elementos físicos, mas também de sentimentos, odores, cores e movimentos. Os elementos da

\begin{tabular}{|l|l|}
\hline $\begin{array}{l}\text { Daqui há alguns anos, o que vocé } \\
\text { acha que mudará nessa } \\
\text { paisagem? }\end{array}$ & \\
\hline $\begin{array}{l}\text { Oque vocé mudaria nessa } \\
\text { paisagem? }\end{array}$ & \\
\hline
\end{tabular}

A leitura indireta da paisagem é feita por meio da análise de imagens, vídeos, relatos que retratam a realidade. Agora que vocé já conhece o conceito de paisagem, vamos aprender sobre a interferência humana na paisagem cotidiana, utilizando-o como ferramenta de reflexăo. A seguir, faremos a análise de algumas paisagens e responderemos a algumas questóes sobre elas. Esteja atento à explicação

\begin{tabular}{l} 
Significado Funcional - Funçäo Material \\
\begin{tabular}{|l|l|}
\hline $\begin{array}{l}\text { Quais elementos vocế observa } \\
\text { nessa paisagem? }\end{array}$ & \\
\hline Quais os principais elementos \\
dessa paisagem? Explique. & \\
\hline Qual é a ligaçăo entre os & \\
elementos \\
observados? Explique. & \\
\hline Quais os agentes sociais fazem e & \\
refazem a paisagem observada? & \\
(comércio, indústria, poder & \\
público, religiáo, comunidade em \\
geral, grupos sociais excluídos).
\end{tabular} \\
\hline
\end{tabular}

Significado Simbólico - Funçäo Imaterial

\begin{tabular}{|l|l|}
\hline $\begin{array}{l}\text { O que vocé sente ao observar } \\
\text { essa paisagem? }\end{array}$ & \\
\hline O que ela comunica para vocé? & \\
\hline $\begin{array}{l}\text { Vocé sente vontade de } \\
\text { transformá-la de alguma } \\
\text { maneira? }\end{array}$ & \\
\hline
\end{tabular}

Significado de Projeçăo - Funçăo Futura

\section{Leitura direta da paisagem}

A expediçăo geográfica

A leitura direta acontece quando estamos em contato com a paisagem a ser analisada. Para realizar essa leitura, vamos a campo em uma expediçăo geográfica pelo bairro no entorno da escola. Para isso, algumas coisas são de extrema importância e năo deveremos esquecer. Marque um $\mathrm{X}$ naquilo que já está preparado:

Nosso guia de leitura da paisagem

Um caderno ou uma prancheta para apoiar os papéis

O Lápis e borracha.

O Máquina fotográfica ou celular que tire fotos.

O̧ Garrafa d'água

$\bigcirc$ Protetor solar.

Mapa do trajeto:

(Adicionar mapa do trajeto)

Fique atento aos detalhes da paisagem. Faça a leitura das questões e vá pensando nas respostas. Vocé poderá escrever sobre o que está vendo na caixa de observaçőes e deverá desenvolver um desenho sobre alguma paisagem que mais chame a atençăo e que demonstre as marcas da desigualdade social. Observe, descreva e análise tudo que sua visão abarca. 
Onde estou (Cidade, Estado, País)?

Em que dia, més e ano estou?

Qual a estação do ano?

Como está o dia hoje?

Horário de saída:

Horário de chegada:

Ponto 1:

Significado funcional - Funçăo material

\begin{tabular}{|l|l|}
\hline \multicolumn{2}{|c}{ Suagnificado funcional - Funçăo material } \\
nessa paisagem?
\end{tabular}

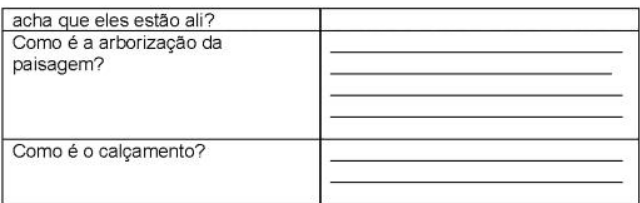

Significado Simbólico - Função Imaterial

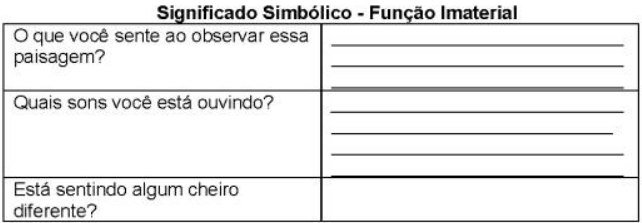

diferente?

Significado de Projeção - Funçăo Futura

Daqui há alguns anos, o que

você acha qu

Oque vocé mudaria nessa

paisagem?

Ponto 2:

Significado funcional - Funçăo materia

\begin{tabular}{|l|l|}
\multicolumn{2}{c}{ Significado funcional - Funçăo material } \\
\begin{tabular}{|l|l}
\hline $\begin{array}{l}\text { Quais elementos vocé observa } \\
\text { nessa paisagem? }\end{array}$ & \\
\cline { 2 - 2 } & \\
\hline Quais os principais elementos & \\
\hline
\end{tabular}
\end{tabular}

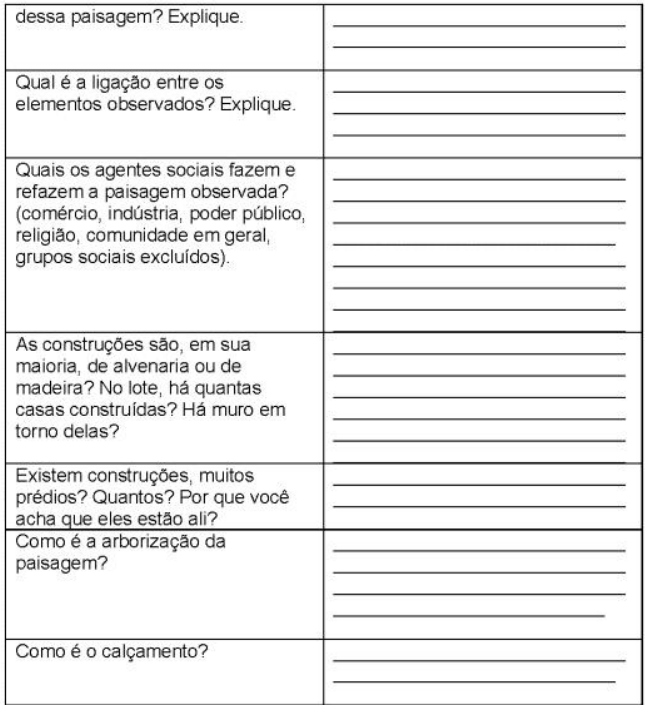

Significado Simbólico - Função Imaterial O que você sente ao observar essa paisagem?

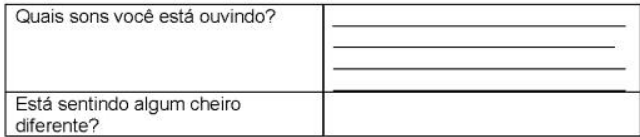

Significado de Projeçăo - Funçăo Futura

\begin{tabular}{|c|c|}
\hline $\begin{array}{l}\text { Daqui há alguns anos o que } \\
\text { vocé acha que mudará nessa } \\
\text { paisagem? }\end{array}$ & \\
\hline $\begin{array}{l}\text { O que você mudaria nessa } \\
\text { paisagem? }\end{array}$ & \\
\hline
\end{tabular}

Ponto 3:

Significado funcional - Funçăo material

\begin{tabular}{|l|l|}
\hline $\begin{array}{l}\text { Quais elementos vocé observa } \\
\text { nessa paisagem? }\end{array}$ & \\
\hline $\begin{array}{l}\text { Quais os principais elementos } \\
\text { dessa paisagem? Explique. }\end{array}$ & \\
\hline & \\
\hline Qual é a ligação entre os & \\
\hline
\end{tabular}



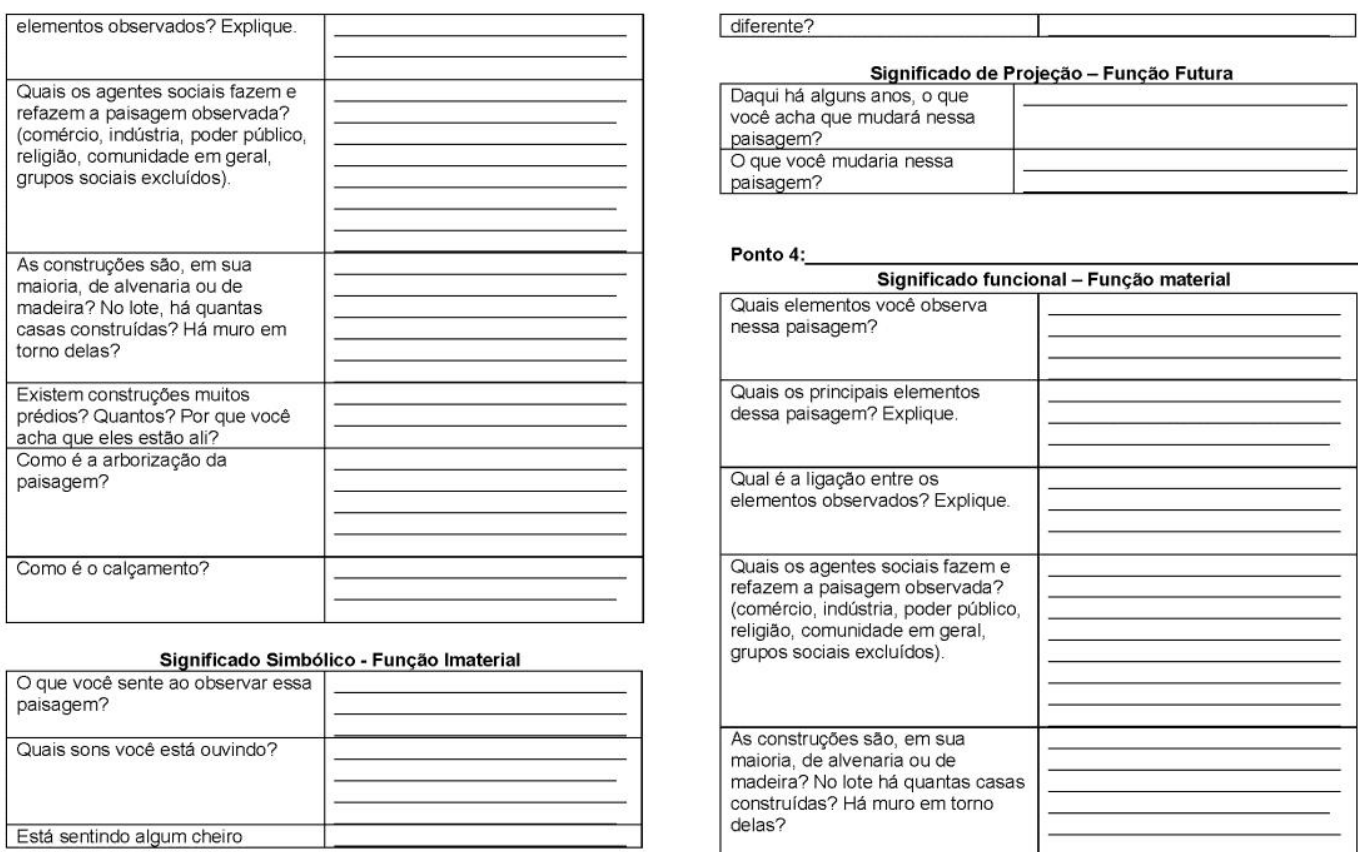

Ponto 4:

Significado funcional - Funçăo material

Quais elementos vocé observa

nessa paisagem?

Quais os principais elementos

dessa paisagem? Explique.

Qual é a ligaçăo entre os

elementos observados? Explique

Quais os agentes sociais fazem $\mathrm{e}$

refazem a paisagem observada?

(comercio, industria, poder publico,

grupos sociais excluidos).

As construçōes săo, em sua
maioria, de alvenaria ou de

madeira? No lote há quantas casas

construídas? Há muro em torno

delas?

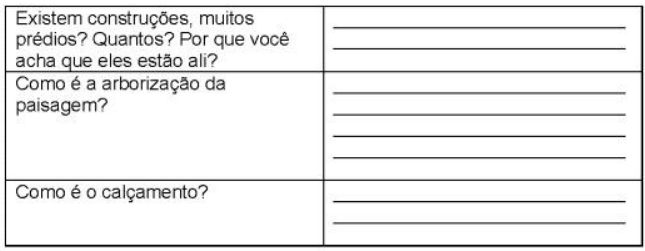

Significado Simbólico - Funçăo Imaterial

\begin{tabular}{|l|l|}
\hline $\begin{array}{l}\text { O que você sente ao observar essa } \\
\text { paisagem? }\end{array}$ & \\
\hline Quais sons você está ouvindo? & \\
\hline $\begin{array}{l}\text { Está sentindo algum cheiro } \\
\text { diferente? }\end{array}$ & \\
\hline
\end{tabular}

Significado de Projeção - Função Futura

\begin{tabular}{|l|l|}
\hline $\begin{array}{l}\text { Daqui há alguns anos, o que } \\
\text { vocé acha que mudará nessa } \\
\text { paisagem? }\end{array}$ & \\
\hline $\begin{array}{l}\text { Oque vocé mudaria nessa } \\
\text { paisagem? }\end{array}$ & \\
\hline
\end{tabular}

O que vocé

paisagem?

Anotaçōes:

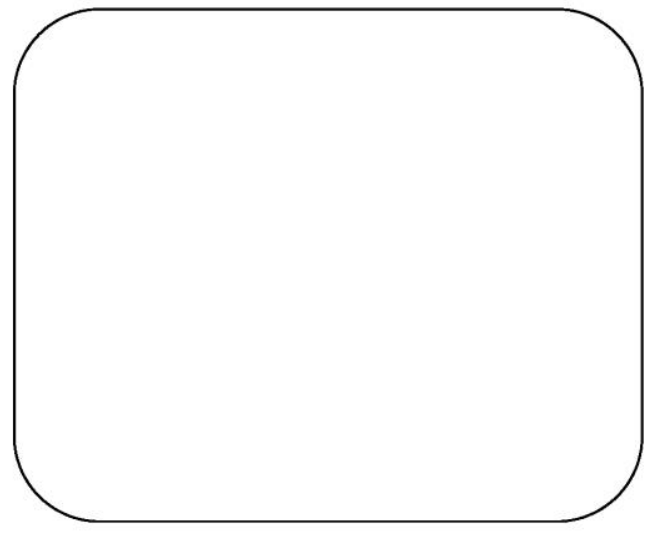

' Os nomes apresentados são fictícios, a fim de garantir a confidencialidade das informações e o anonimato. Optou-se por preservar a grafia original das respostas dos alunos. 